\title{
Congenital Structural Myopathy
}

National Cancer Institute

\section{Source}

National Cancer Institute. Congenital Structural Myopathy. NCI Thesaurus. Code C84648.

A group of rare genetic muscle disorders characterized by hypotonia, muscle weakness, and delayed development of motor skills. 